\section{Trade Unions in Industry}

As part of a general production drive, the Trades Union Congress is inviting trade unionists to extend their knowledge of management in industry. Through its publicity organ Industrial News, the Congress has announced that it is co-operating with the National Institute of Industrial Psychology, the British Institute of Management, the Government Committee on Industrial Productivity and the Administrative Staff College in seeking ways to make workshops more happy and efficient places. Experiments are to be carried out on the problems of the effects of boredom in industry, the means of minimizing labour turnover and the training of new employees. The Trades Union Congress is asking members of trade unions to co-operate with these organisations by seeking goodwill for their officers at places suitable for experiment.

\section{Cultivation of Root Vegetables}

Buluetin No. 120 of the Ministry of Agriculture and Fisheries (H.M. Stationery Office. 9d. net) deals with all phases of the commercial cultivation of carrots, beetroot, parsnips, turnips, swedes and other minor root crops. A new revision (August 1947) of the third edition has recently appeared, and brings the subject-matter up to date. The most modern additions deal with row-crop cultivation, irrigation, and the control of weeds.

\section{Precession of an Unsymmetrical Top}

IT has been known since the time of Lagrange's "Mécanique Analytique" (1788) that a rigid body smoothly pivoted at one of its points $O$ and symmetrical about an axis passing through $O$ can have steady motions of precession in which the axis of symmetry rotates uniformly about the vertical while the solid itself rotates uniformly about the axis of symmetry; but it has been generally supposed that there is no corresponding result if the body is unsymmetrical. However, G. Grioli (Annali di Mathematica, 26, 1 ; 1947, and Rendiconti dell' Accademia Nazionale dei Lincei, 4, 420 ; 1948) has shown that under certain conditions we can have steady precession of an unsymmetrical body about a non-vertical axis. If $G$ is the centre of mass, it is necessary that $O G$ should be perpendicular to one of the two circular sections of the momental ellipsoid at $G$, and that the axis of precession should be inclined to the vertical at a definite angle which can be calculated from the same momental ellipsoid. If these conditions are satisfied, there is a doubly infinite set of motions in which $O G$ is perpendicular to the axis of precession, and the solid rotates uniformly about $O G$ in the same time as $O G$ rotates uniformly about the non-vertical axis of precession.

\section{Geotectonic Map of North-west Germany}

LAST year the first German publication on scientific geology since the War was issued by the Reichsamt der Bodenforschung, Hanover, namely, a general geotectonic map of north-west Germany, scale 1 : 100,000 (15 sheets, 200 marks). This map comprises all wells and geological as well as geophysical results from 1934 up to 1945 . The new map is supplemented by formation data, stratigraphic symbols, profiles, surface contour lines, data of the depths, and geophysical data. Moreover, there is attached a general map, scale $1: 1,000,000$, of the structures and two hundred salt domes in this area. A volume of annotations_of the map is projected.

\section{Society for Visiting Scientists}

THE Society for Visiting Scientists (5 Old Burlington Street, London, W.1) has been able to extend its facilities and membership for scientific workers resident in the United Kingdom. The number of such members is no longer limited, and applications for membership from scientific workers interested in the Society's aims will be welcomed by the Executive Committee. Applicants should apply to the Assistant Secretary, mentioning one or more members of the Society who would be willing to be their sponsors. The subscription for members resident in the United Kingdom is three guineas per annum, with an entrance fee of one guinea. Visiting scientists from overseas are charged an entrance fee of five shillings only, and pay an annual subscription only if they reside in the United Kingdom for more than six months. The Society now has more than 1,300 members, about 1,170 of whom are overseas. In addition to the opportunity of meeting visiting scientists, and thus furthering intermational contact and friendship among men of science, the Society's premises offer useful club facilities.

\section{National Foundation for Scientific Research, Brussels}

THE twentieth annual report of the National Foundation for Scientific Research, Brussels, for the year 1946-47, gives lists of members of the various commissions, and a note on the Inter-University Institute of Nuclear Physics. It also includes full details of the forty-five research grants made for the year 1947-48, amounting to $2,062,500$ francs, and an analysis of the distribution of grants made since the establishment of the Foundation. Special grants for the period 1947-48 have been allotted to $M$. Biquet for sinking wells in water-bearing strata for the study of the freezing of dead ground at great depths (150,000 francs); to Prof. F. Mayence for excavation at Apamée (100,000 francs); to MM. Gratia, Florkin, Massart and Desreux for completing the existing installation of apparatus for electrophoresis by a high-quality optical apparatus of the Klett or Pearson type (100,000 francs); and to Prof. Piccard and Prof. Cosyns for submarine investigations at great depths. A list of publications during the year by those receiving grants during 1945-47, arranged under authors' names, is appended.

\section{International Union of Crystallography}

THE first General Assembly and Congress of the recently formed International Union of Crystallography was held at Harvard University, Cambridge, Mass., during July 28-August 3 and was attended by some 350 crystallographers of ten nations. In recognition of his epoch-making contribution to the modern development of the subject, Prof. M. von Laue (Germany) was unanimously elected honorary president of the Union. Officers were elected as follows: President, Sir Lawrence Bragg (Great Britain); Vice-Presidents, A. Westgren (Sweden), R. W. G. Wyckoff (United States); General Secretary, R. C. Evans (Crystallographic Laboratory, Cavendish Laboratory, Cambridge); other members of the Executive Committee are M. J. Buerger (United States), P. P. Ewald (Great Britain), A. L. Patterson (United States), J. Wyart (France). Statutes and by- 